NASA Technical Memorandum 107124 AIAA-96-0218

\title{
Calculation of Kinetic Rate Constants From Thermodynamic Data
}

C. John Marek

Lewis Research Center

Cleveland, Ohio

Prepared for the

34th Aerospace Sciences Meeting \& Exhibit sponsored by the American Institute of Aeronautics and Astronautics Reno, Nevada, January 15-18, 1996

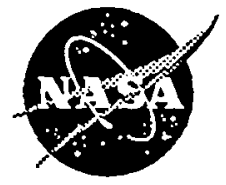

National Aeronautics and Space Administration
Lenericon

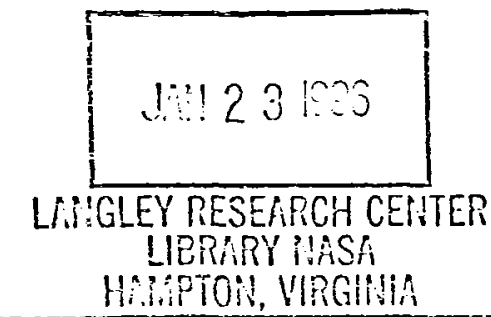




\title{
Calculation of Kinetic Rate Constants
}

\section{from Thermodynamic Data}

\author{
C. John Marek \\ National Aeronautics and Space Administration \\ Lewis Research Center \\ Cleveland, Ohio 44135
}

\begin{abstract}
A new scheme for relating the absolute value for the kinetic rate constant $k$ to the thermodynamic constant $K_{p}$ is developed for gases. In this report the forward and reverse rate constants are individually related to the thermodynamic data. The kinetic rate constants computed from thermodynamics compare well with the current kinetic rate constants. This method is self consistent and does not have extensive rules. It is first demonstrated and calibrated by computing the $\mathrm{HBr}$ reaction from $\mathrm{H}_{2}$ and $\mathrm{Br}_{2}$. The method then is used on other reactions.
\end{abstract}

\section{Symbols}

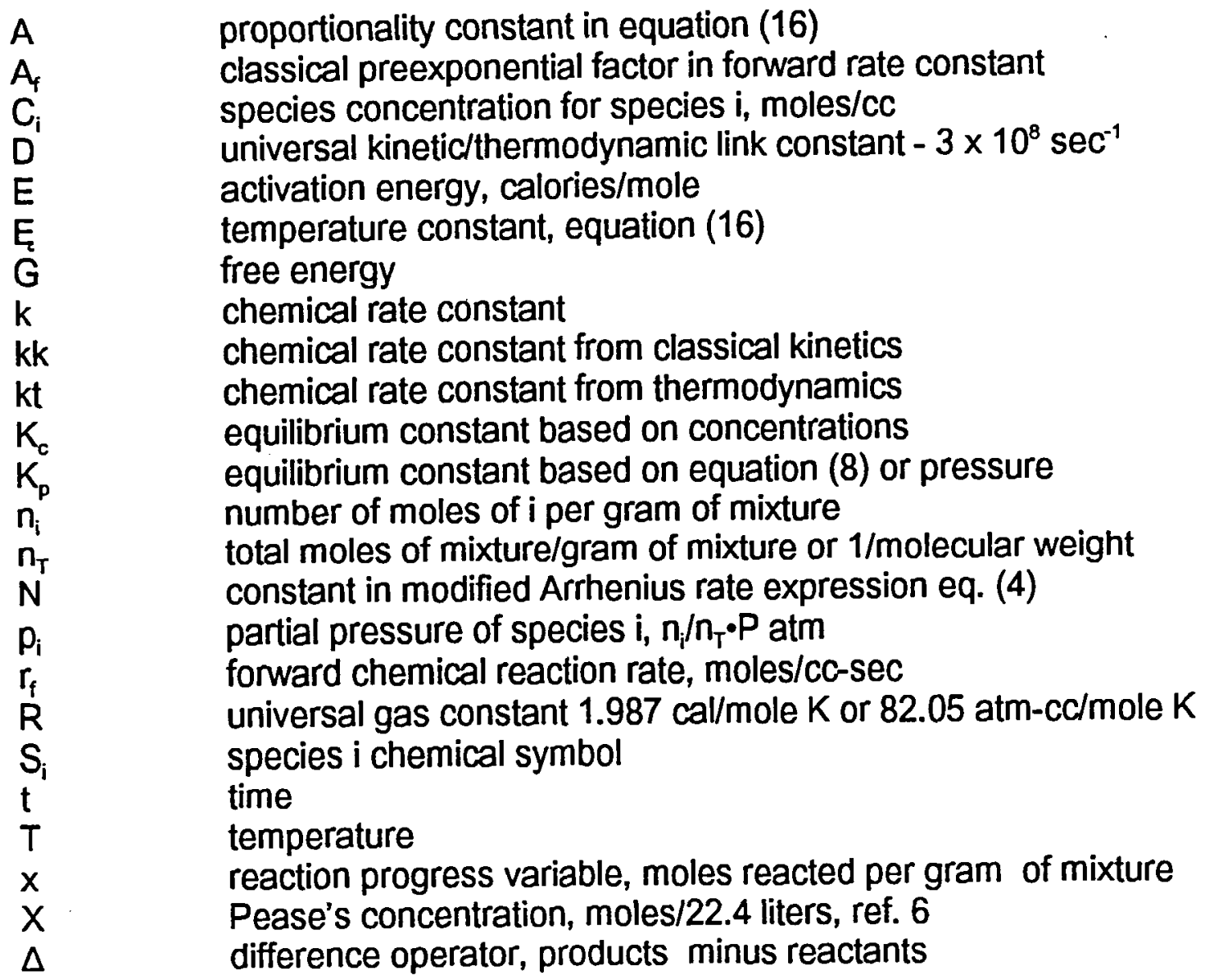

Copyright () 1996 by the American Institute of Aeronautics and Astronautics, Inc. No copyright is asserted in the United States under Title 17, U.S. Code. The U.S. Government has a royalty-free license to exercise all rights under the copyright claimed herein for government purposes. All other rights are reserved by the copyright owner. 
$\begin{array}{ll}\mu_{i}^{\circ} & \text { standard chemical potential for species } i \\ \mathbf{v}_{i} & \text { stoichiometric molar coefficient for species } i\end{array}$

subscripts:

c

f

i

$p$

r

value expressed in terms of concentration

forward direction

for each species i

value expressed in terms of pressure

reverse direction

\section{Introduction}

There are several reasons why it would be desirable to relate the kinetic rate constants to thermodynamic data. First, modern kinetic models contain many reactions with many constants to form large mechanisms. These systems are not universal and are complex to assemble from the experimental data base. Thermodynamic equilibrium calculations, on the other hand, have been simplified and systematized and are only species dependent. Thus, relating the kinetic constants to thermodynamics might reduce the work involved in doing kinetic calculations.

Secondly many kinetic constants are still unknown: these could be computed by using thermodynamic data; thus, the kinetics calculation could be done without performing more experiments.

The derived relationship that links the chemical rate constants to thermodynamics is the ratio equation (1), where the thermodynamic equilibrium constant $K_{c}$ has been established as the forward rate constant $k_{f}$ over the reverse rate constant $k_{r}$ :

$$
\mathrm{K}_{\mathrm{c}}=\frac{\mathrm{k}_{\mathrm{f}}}{\mathrm{k}_{\mathrm{r}}} .
$$

Normally one thinks of kinetics as a path process, but the kinetic rate constants are state variables like $K_{c}$. The kinetic constants $k$ are functions only of temperature and are therefore state variables and not path variables. Equation (1) holds not only at equilibrium, but also at every point of the reaction from initial conditions to final state; furthermore, it is independent of concentration. 
The first hurdle to developing an overall relationship between kinetics and thermodynamics is to overcome the idea that this is impossible. All of the kinetic text books principally state that thermodynamics is only for equilibrium calculations whereas kinetics describes the rate of approach to equilibrium; thus, they state that thermodynamics would not be useful for kinetics calculations. However, as stated, relationship (1) holds for all time, not only at equilibrium. Thus, with thermodynamics, the complete energy surface is available for ideal gas mixtures for all compositions, not only for equilibrium states (from initial reactants to final products). This information can be used to compute the kinetic rate constants. The change of system free energy with reaction $\partial \mathrm{G} / \partial \mathrm{x}$ is known, and is used to compute the kinetic rate constants.

A second hurdle is the idea that reacting molecules have to go through an activated complex energy barrier to complete the reaction. This state may be estimated from transition state theory to determine the kinetic constants but would be difficult to compute from thermodynamics. But thermodynamics is involved in equation (1). Are the activated complex states the same for both reaction directions? Does the activated complex state would depend on the starting point?

A connection between thermodynamics and the chemical kinetics constants is presented with comparisons to experimental data.

\section{Description of the Method}

The classical kinetic method can be described for a particular rate by:

$$
v_{1} S_{1}+v_{2} S_{2}=v_{3} S_{3}+v_{4} S_{4} \text {, }
$$

where the $v_{i}$ are the stoichiometric coefficients for species $\mathrm{S}_{i}$. The forward rate $r_{\mathrm{f}}$ is given by:

$$
\mathrm{r}_{\mathrm{f}}=\mathrm{k}_{\mathrm{f}} \mathrm{C}_{1}^{\mathrm{v}_{1}} \mathrm{C}_{2}^{\mathrm{v}_{2}}
$$

and the kinetic rate constant $k_{f}$ is defined as:

$$
\mathrm{k}_{\mathrm{f}}=\mathrm{A}_{\mathrm{f}} \mathrm{T}^{\mathrm{N}} \exp (-\mathrm{E} / \mathrm{RT})
$$

In the thermodynamic derivation, the kinetic rate is assumed to be related to the gradient of the free energy or: 


$$
\mathrm{r}_{\mathrm{f}} \propto \exp \left(\frac{-1}{\mathrm{RT}} \frac{\partial \mathrm{G}}{\partial \mathrm{x}}\right)
$$

The free energy $G$, ref. 1 , is given by:

$$
G=\sum_{i}\left(\mu_{i}^{o} n_{i}\right)+\sum_{i}\left(n_{i} R T \ln \left(p_{i}\right)\right)
$$

Differentiating $\mathrm{G}$ with respect to the reaction progress variable $\mathrm{x}$, and using the facts that $\left(\partial n_{T} / \partial x=-\Delta v_{i}\right)$; for reactants, $\left(-v_{i} \partial / \partial n_{i}=\partial / \partial x\right)$; and for products, $\left(v_{i} \partial / \partial n_{i}=\partial / \partial x\right)$ with equation (2) as the model, this results in:

$$
-\frac{1}{R T} \frac{\partial G}{\partial x}=\sum_{i} \frac{v_{\mathrm{fi}} \mu_{\mathrm{fi}}^{o}}{R T}-\sum_{i} \frac{v_{\mathrm{ri}} \mu_{\mathrm{ri}}^{\mathrm{o}}}{\mathrm{RT}}+\sum_{\mathrm{i}}\left(v_{\mathrm{fi}} \ln p_{\mathrm{fi}}\right)-\sum_{i}\left(v_{\mathrm{ri}} \ln p_{\mathrm{ri}}\right) \text {. }
$$

At equilibrium, the free energy is a minimum, $\partial G / \partial x=0$, with the equilibrium constant $\mathrm{K}_{\mathrm{p}}$ given by:

$$
\mathrm{K}_{\mathrm{p}}=\exp \left(\sum_{\mathrm{i}} \frac{v_{\mathrm{f}} \mu_{\mathrm{fi}}^{\mathrm{o}}}{\mathrm{RT}}-\sum_{\mathrm{i}} \frac{v_{\mathrm{ri}} \mu_{\mathrm{ri}}^{\circ}}{\mathrm{RT}}\right)=\left.\frac{\mathrm{p}_{3}^{v 3} \mathrm{p}_{4}^{v 4}}{\mathrm{p}_{1}^{v 1} \mathrm{p}_{2}^{v 2}}\right|_{\text {at equilibrium }}
$$

The LHS is the thermodynamic expression for $\mathrm{K}_{\mathrm{p}}$, expressed as:

$$
\mathrm{K}_{\mathrm{p}}=\exp \left(\frac{-\Delta \mathrm{G}^{\circ}}{\mathrm{RT}}\right),
$$

and is independent of composition or degree of reaction. In addition $\mathrm{K}_{c}$ is given by:

$$
\mathrm{K}_{\mathrm{c}}=\mathrm{K}_{\mathrm{p}}(\mathrm{RT})^{-\Delta v_{\mathrm{i}}}=\mathrm{K}_{\mathrm{p}}(\mathrm{RT})^{\left(\Sigma v_{\mathrm{fi}}-\Sigma v_{\mathrm{r}}\right)}
$$

At this point, it is important to distinguish chemical kinetic constants, $k_{p}$ and $k_{c}$. When the kinetic rate is given in terms of concentrations, $k_{c}$ is used; and when the rate is given in terms of pressure $p, k_{p}$ is utilized.

Then:

$$
\frac{\mathrm{dc}}{\mathrm{dt}}=\mathrm{k}_{\mathrm{c}} \mathrm{C}_{1}^{v_{1}} \mathrm{C}_{2}^{v_{2}} ; \frac{\mathrm{dp}}{\mathrm{dt}}=\mathrm{k}_{\mathrm{p}} \mathrm{p}_{1}^{v_{1}} \mathrm{p}_{2}^{v_{2}} ; \mathrm{C}_{\mathrm{i}}=\frac{\mathrm{p}_{\mathrm{i}}}{\mathrm{RT}}
$$

$$
\mathrm{k}_{\mathrm{c}}=\mathrm{k}_{\mathrm{p}}(\mathrm{RT})^{\left(\Sigma \mathrm{v}_{\mathrm{f}}-1\right)} \text {; }
$$


similar to $K_{p}$ and $K_{c}$ in equation (10).

Returning to equations (5) and (7) and equating the pressure terms (ie. the concentration terms) to the concentration terms in equation (3), one obtains:

$$
\mathrm{k}_{\mathrm{cf}}=\mathrm{DK}_{\mathrm{p}}(\mathrm{RT})^{\Sigma v_{\mathrm{fi}}-1} \text { for } \mathrm{K}_{\mathrm{p}}<1
$$

where $D$ is a constant to be determined. Note that equation (7) is written for the net rate, whereas equation (3) is for the forward rate. Equation (12) provides the connection between thermodynamics and the forward chemical kinetic constant that shall be used.

Equation (12) without the inequality cannot hold for both the forward and reverse rates because equation (1) would not be satisfied. Remember that $K_{p r}=1 / K_{p f}$, so when $K_{p i}<1$, then $K_{p r}>1$. To satisfy the kinetic constant ratio equation (1), the reverse rate must be given by:

$$
\mathrm{k}_{\mathrm{cr}}=\mathrm{D}(\mathrm{RT})^{\Sigma v_{\mathrm{i}}-1} \text { for } \mathrm{K}_{\mathrm{pr}}>1
$$

$D$ is an unknown, assumed universal constant. It was determined from the fit of the $\mathrm{HBr}$ data presented in the next section. It was found to be $3 \times 10^{8} \mathrm{sec}^{-1}$ which is used throughout this report.

The results from the thermodynamic method using equations (12) and (13) to compute the kinetics for all reactions are compared with experimental data. If the chemical potential of the products is greater than the reactants, then $\mathrm{K}_{\mathrm{p}}<1$, and equation (12) is used. If the chemical potential of the products is less than the reactants, then the reaction is a cascade reaction with $\mathrm{K}_{\mathrm{p}}>1$, and equation (13) is used. In this formulation only a single constant $D$ and the thermodynamic base is sufficient to determine the whole kinetic data base.

In the next section the hydrogen bromine reactions are discussed, followed by a subset of the $\mathrm{H} / \mathrm{O}$ reactions. In the final section, a random selection of rates chosen from reference 4, NSRDS, are presented for comparison. 


\section{Calibration and Demonstration of Thermodynamic Kinetics Method using the Hydrogen-Bromine Reactions}

The $\mathrm{HBr}$ system was chosen for several reasons. It was simple, but yet had interesting complexities. First there are only 5 species involved and they are all in the thermodynamic data set. They are arranged with $\mathrm{HBr}$ in the middle as follows:

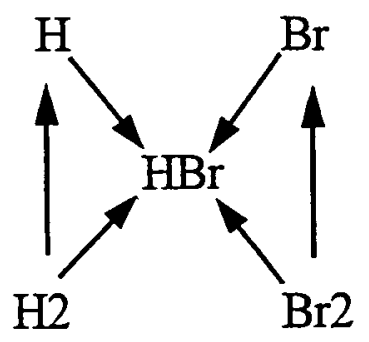

Secondly, the three classical rates to describe the system are:

$$
\begin{array}{rlrl}
2 \mathrm{Br} & =\mathrm{Br} 2^{*} & \mathrm{C} 1 & \mathrm{~A}=1.67 \mathrm{E}+14, \mathrm{n}=0 ., \mathrm{E}=-1844 . \\
\mathrm{Br}+\mathrm{H}_{2} & =\mathrm{HBr}+\mathrm{H} & \mathrm{C} 2 & \mathrm{~A}=3.4 \quad \mathrm{E}+12, \mathrm{n}=0.5, \mathrm{E}=18300 . \\
\mathrm{HBr}+\mathrm{Br} & =\mathrm{H}+\mathrm{Br}_{2} & \mathrm{C} 3 & \mathrm{~A}=8.13 \mathrm{E}+12, \mathrm{n}=0.5, \mathrm{E}=44500 .
\end{array}
$$

*At low temperatures $M$ is not included, data is from ref. 3.

These are called "elementary reaction rates," because kineticists believe they represent the specie combinations by which the reaction proceeds. The rates for the three reactions are well known and the computed data can be treated like experimental data to match with other prediction methods.

Finally, the overall classical rate for $\mathrm{HBr}$ formation is given by:

$$
\frac{\mathrm{d}(\mathrm{HBr})}{\mathrm{dt}}=\frac{\mathrm{k}\left[\mathrm{H}_{2}\right]\left[\mathrm{Br}_{2}\right]^{1 / 2}}{5 .+\frac{[\mathrm{HBr}]}{\left[\mathrm{Br}_{2}\right]}}
$$

The rate is inhibited by the $\mathrm{HBr}$ product. This is one of the first systems where a mechanism could be written down and solved.

\section{Thermodynamic approach}

In order to obtain the constant $D$, only one point is required. The formation of $\mathrm{HBr}$ at $574.3 \mathrm{~K}$, table 2 , was used to determine its value at $3 \times 10^{8}$. Individual 
rate comparisons are presented, followed by the predictions of the concentrations.

The classical mechanism rates above (equation (14)) with the thermodynamic predictions could have been used to make concentration predictions. However, a generalized equation set was chosen. All possible reactions are written down to maintain material balances. In computing thermodynamic equilibrium, all species are considered.

For the thermodynamic method, all six interaction equations are listed below in Table 1:

Table 1. Reactions for the Thermodynamic Hydrogen-Bromine Mechanism

\begin{tabular}{|c|c|c|c|}
\hline Equation & Name & $\mathrm{K}_{\mathrm{p}}$ at $574.3 \mathrm{~K}$ & $\begin{array}{c}\mathrm{k}_{\mathrm{cf}} \mathrm{cc}-\mathrm{mol}-\mathrm{sec} \text { units } \\
\text { at } 574.3 \mathrm{~K}\end{array}$ \\
\hline $\mathrm{Br}_{2}=2 \mathrm{Br}$ & $\mathrm{T} 1$ & $9.32 \mathrm{E}-13$ & $2.90 \mathrm{E}-4$ \\
\hline $\mathrm{H}_{2}=2 \mathrm{H}$ & $\mathrm{T} 2$ & $4.10 \mathrm{E}-35$ & $1.24 \mathrm{E}-26$ \\
\hline $0.5 \mathrm{H}_{2}+\mathrm{Br}=\mathrm{HBr}$ & $\mathrm{T} 3$ & $1.81 \mathrm{E} 11$ & $6.51 \mathrm{E} 10$ \\
\hline $\mathrm{H}+0.5 \mathrm{Br}_{2}=\mathrm{HBr}$ & $\mathrm{T} 4$ & $2.73 \mathrm{E} 22$ & $6.51 \mathrm{E} 10$ \\
\hline $\mathrm{H}+\mathrm{Br}=\mathrm{HBr}$ & $\mathrm{T} 5$ & $2.82 \mathrm{E} 28$ & $1.41 \mathrm{E} 13$ \\
\hline $0.5 \mathrm{H}_{2}+0.5 \mathrm{Br}_{2}=\mathrm{HBr}$ & $\mathrm{T} 6$ & $1.74 \mathrm{E} 5$ & $3.0 \mathrm{E} 8$ \\
\hline
\end{tabular}

One way to compare the above two methods is to use an empirical least squares fit of $\mathrm{K}_{\mathrm{p}}$ as a function of $\mathrm{T}$, as in the last section of reference 4 , in the form:

$$
K_{p}=A \exp \left(E_{\varepsilon} / R T\right) \text {. }
$$

For bimolecular reactions where $K_{p}<1, k_{f}$ would equal $A(D R T) \exp \left(E_{q} / R T\right)$ - a form similar to the Arrhenius expression, equation (4). Comparing $E_{\varepsilon}$ to $E$ gave a hint of the desired correlation. This comparison has slightly different numbers, but it looked reasonable. -

A better method is to plot the two relationships versus temperature. A comparison of the $\mathrm{C} 2$ and RC3 kinetics constants by the two methods are shown in figure 1. Equation (12) works well for $\mathrm{C} 2$ while equation (13) works for RC3. For RC3 the methods agree at lower temperature, but diverge at higher temperature. The classical relation may be extrapolated out of its range. 


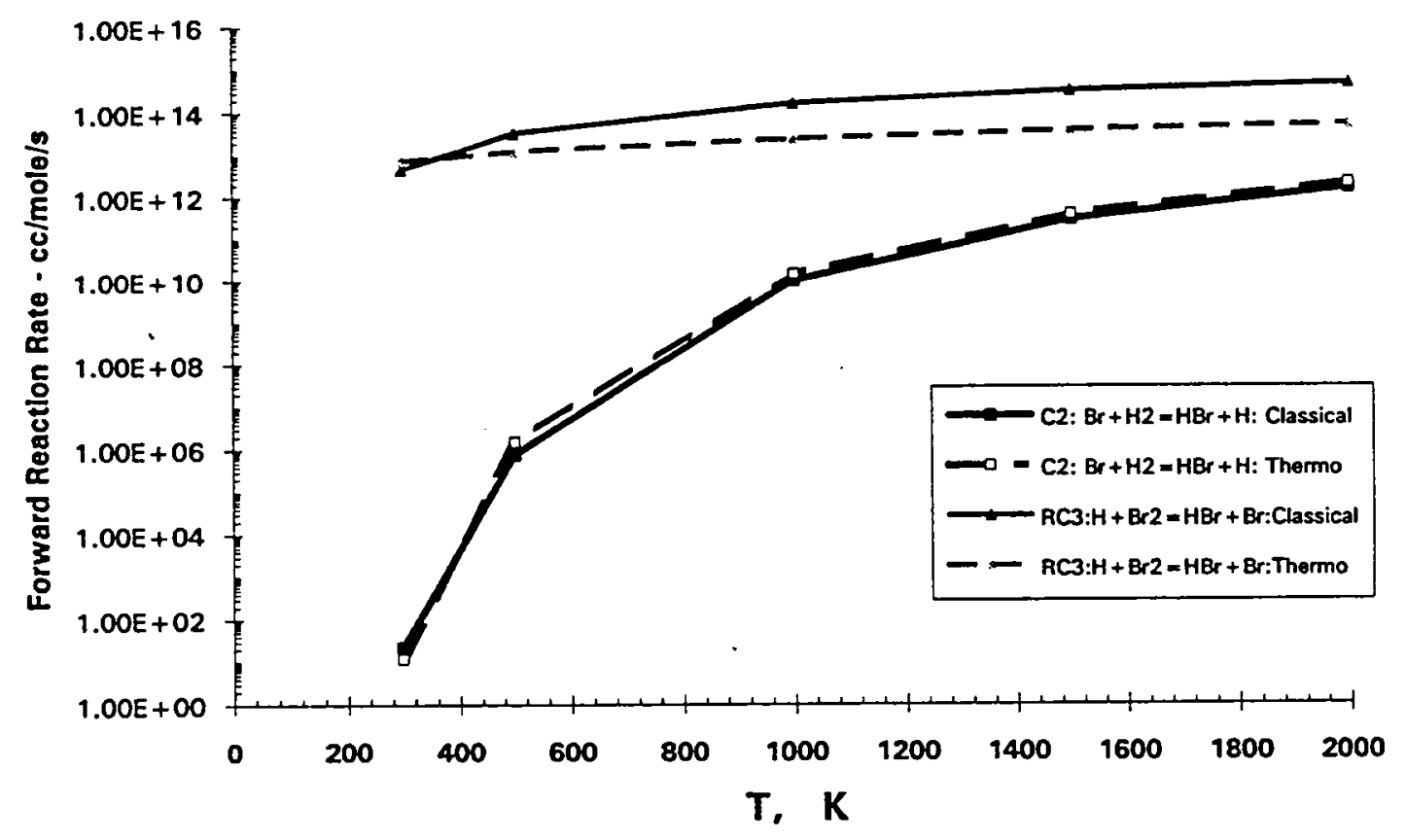

Figure 1. Comparison of classical kinetic equations and thermodynamic predictions for equations $\mathrm{C} 2$ and RC3.

The two methods for atom/atom recombinations are shown in figure 2. Differences between the two methods range from $10^{-3}$ to $10^{6}$, but the curves follow the same trend. $1.00 E+20$

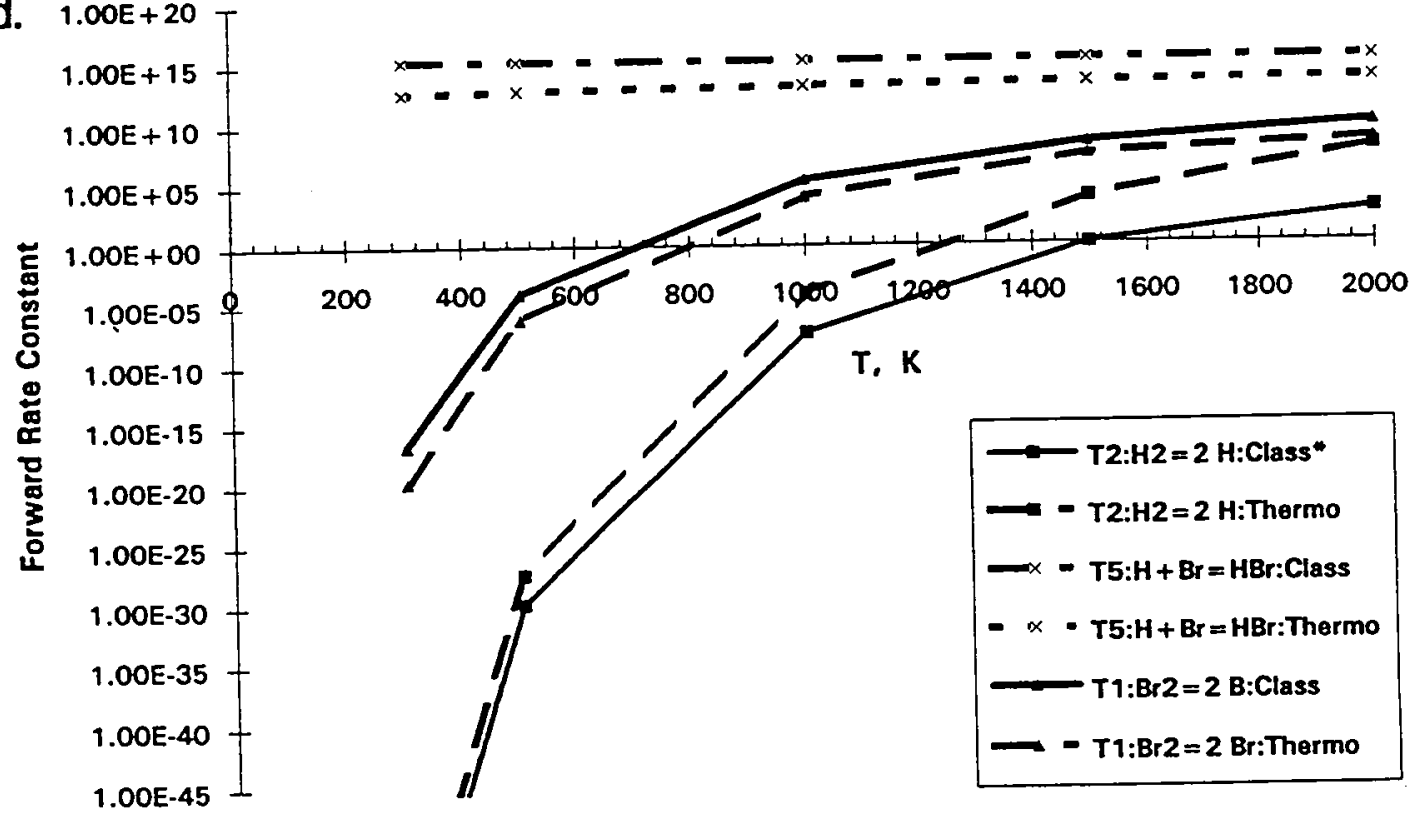

Figure 2. Comparison of classical kinetic equations and thermodynamic predictions for atom reactions using equation (12) and (13). 
A better comparison is obtained by plotting the ratio of the thermodynamic $\mathrm{HBr}$ rates, $\mathrm{kt}$, to classical kinetic rates, $\mathrm{kk}$, versus temperature in figure 3 . A value of one indicates perfect agreement. Using $D$ of $3.0 \times 10^{8}$, the thermodynamic rates are given by equations (12) and (13).

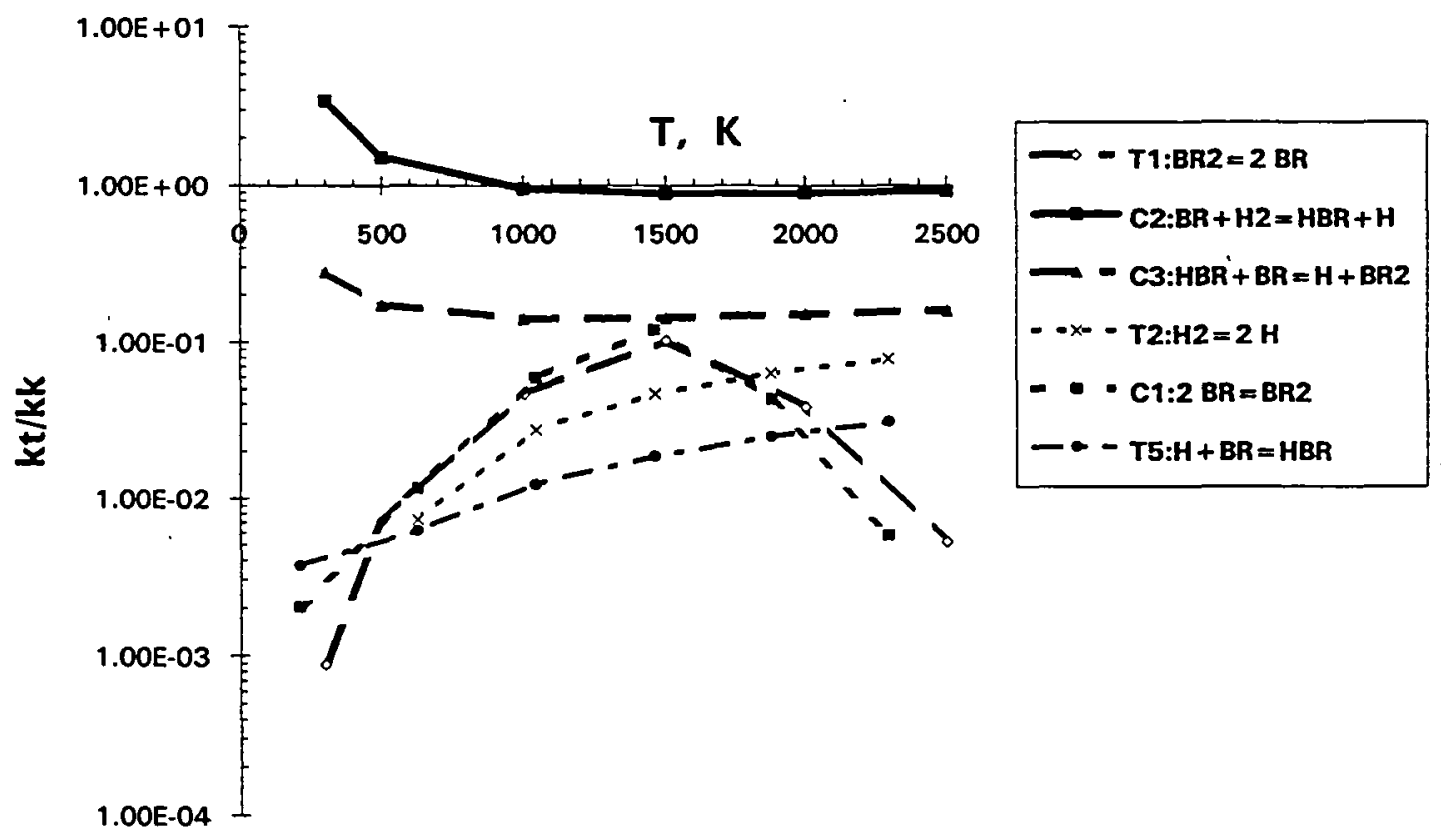

Figure 3: Ratio of thermodynamic rate to kinetic rate versus temperature

Rate $\mathrm{C} 2$ agrees very well over a wide temperature range. For rate $\mathrm{C} 3$, the ratio is $1 / 10$ the classical; and for the other rates, the ratio at $500 \mathrm{~K}$ is $1 / 100.500 \mathrm{~K}$ is the temperature range where the experimental data is compared. The maximum in the $\mathrm{Br}$ curves is caused by $\mathrm{K}_{\mathrm{p}}$ going through one at approximately $1500 \mathrm{~K}$.

Rather than compare individual equations, it is more intuitive to compare the predicted concentrations from the experimental data. The GLSENS program, ref. 5 , is used as the kinetic integrator to compute the concentrations. It can handle global reactions and fractional stoichiometric coefficients.

The conditions of Table 2 were used to obtain the constant $D$. A value of $3 \times 10^{8}$ resulted in a lower prediction 0.1481 at $870 \mathrm{sec}$, compared to data of 0.1559 , but later the predicted results became about 3.5 percent to high. This value produced close agreement with the experimental data. The classical method was 5 percent too low. 
Table 2: $\mathrm{HBr}$ Mole Fraction Data at $574.3 \mathrm{~K} ; \mathrm{p}=1.8 \mathrm{~atm}$; Table XIII of ref. 6. Initial Conditions: $X_{\mathrm{H}_{2}}=0.657 \quad X_{\mathrm{BR}}=0.343$

\begin{tabular}{|c|c|c|c|}
\hline $\begin{array}{c}\text { Time } \\
\text { seconds }\end{array}$ & $\begin{array}{c}\text { Data } \\
X_{\mathrm{HBr}}\end{array}$ & $\begin{array}{c}\text { Classical } \\
\mathrm{X}_{\mathrm{HBr}}\end{array}$ & $\begin{array}{c}\text { Thermodynamic } \\
\mathrm{X}_{\mathrm{HBr}}\end{array}$ \\
\hline 870 & 0.1559 & 0.1404 & 0.1481 \\
\hline 1470 & 0.2295 & 0.2165 & 0.2312 \\
\hline 2070 & 0.2940 & 0.2797 & 0.3014 \\
\hline 2970 & 0.3830 & 0.3559 & 0.3869 \\
\hline 4770 & 0.4877 & 0.4613 & 0.5052 \\
\hline 5970 & 0.5373 & 0.5086 & 0.5568 \\
\hline 7470 & 0.5829 & 0.5512 & 0.6010 \\
\hline 8970 & 0.6102 & 0.5814 & - \\
\hline Equilibrium & 0.686 & & \\
\hline
\end{tabular}

This Table shows a good comparison between both methods and the data.

Reaction T6 $\left(0.5 \mathrm{H}_{2}+0.5 \mathrm{Br}_{2}=\mathrm{HBr}\right.$ is deliberately left out of the reaction set. If reaction T6 (molecule/molecule) is included in the reaction set, the formation of $\mathrm{HBr}$ is very fast with equilibrium being achieved in less than 1 microsecond. Even though $\mathrm{k}$ is small, the concentrations of $\mathrm{H}_{2}$ and $\mathrm{Br}_{2}$ are high, making the overall rate competitive. Thus, rather than reduce $D$ to include this reaction, T6 is left out of the set in order to integrate the rates more like the classical set. When T6 was not included, the net conversion agreed with the experimental data. The results are shown in Table 2.

In order to determine the temperature sensitivity of the reaction sets, Reference 6 tabulates the experimental $k$ of equation (14) versus temperature. The results are tabulated in Table 3 . The comparison is good with additional roll off with $T$ for the thermodynamic set as $T$ decreases.

The decrease in $\mathrm{HBr}$ formation rate with increasing $\mathrm{HBr}$ initial concentration was investigated next, using Table XII of reference 6 for data. The effect of increased initial $\mathrm{HBr}$ concentration is shown in Table 4. The experimental data, given in units of moles/22.4 liters of $\mathrm{H} 2$ was converted to moles/cc of $\mathrm{HBr}$ by:

$$
\mathrm{C}_{\mathrm{HBr}}(\text { moles } / \mathrm{cc})=\mathrm{X}\left(\text { moles } \mathrm{H}_{2} / 22.4 \text { liters }\right) * \frac{2}{22,400 \mathrm{cc}}
$$


Table 3: Predicted Temperature Sensitivity of Reaction Sets and Comparison with Table XIV of ref. 6.

Initial Conditions : $X_{\mathrm{H} 2}=0.657, X_{\mathrm{Br} 2}=0.343$, time $=14.5 \mathrm{~min}$

\begin{tabular}{|c|c|c|c|c|}
\hline Temperature K & $\mathrm{P}_{\mathrm{atm}}$ & $\mathrm{k}_{\text {experimental }}$ & $\mathrm{k}_{\text {classical }}$ & $\mathrm{k}_{\text {thermodynamic }}$ \\
\hline 574.3 & 1.806 & 25.62 & 23.06 & 24.56 \\
\hline 550.5 & 1.731 & 4.760 & 4.862 & 4.186 \\
\hline 524.4 & 1.649 & 0.7782 & 0.7386 & 0.5058 \\
\hline 498.7 & 1.568 & 0.0970 & 0.0950 & 0.0510 \\
\hline
\end{tabular}

${ }^{*}$ values of $\mathrm{k}$ are $(\mathrm{cc} / \mathrm{mole})^{0.5} \mathrm{~min}^{-1}$

Table 4: Effect of Increased Initial $\mathrm{HBr}$ Concentration at $574.3 \mathrm{~K}$ and $25 \mathrm{~min}$. Initial $\mathrm{H} 2$ and $\mathrm{Br} 2=2.009 \mathrm{E}-05$

\begin{tabular}{|c|c|c|c|c|c|c|}
\hline $\begin{array}{c}\text { Initial } \\
\mathrm{HBr}^{+}\end{array}$ & $\mathrm{P}$ atm & $\begin{array}{c}\text { Gain in } \\
\text { Conc. } \mathrm{HBr}\end{array}$ & $\begin{array}{c}\text { Classical } \\
\mathrm{HBr}_{\mathrm{T}}\end{array}$ & $\begin{array}{c}\text { Classical } \\
\Delta \mathrm{HBr}\end{array}$ & $\begin{array}{c}\text { Thermo } \\
\mathrm{HBr}_{\mathrm{T}}\end{array}$ & $\begin{array}{c}\text { Thermo } \\
\Delta \mathrm{HBr}\end{array}$ \\
\hline 0. & 1.89 & $\mathbf{1 . 0 6 6 \mathrm { E } - 5}$ & $8.543 \mathrm{E}-6$ & $\mathbf{8 . 5 4 3 E - 6}$ & $9.20 \mathrm{E}-6$ & $9.20 \mathrm{E}-6$ \\
\hline $4.11 \mathrm{E}-5$ & 3.83 & $\mathbf{9 . 5 4 0 E - 6}$ & $4.81 \mathrm{E}-5$ & $7.0 \mathrm{E}-6$ & $5.49 \mathrm{E}-5$ & $1.38 \mathrm{E}-5$ \\
\hline $5.58 \mathrm{E}-5$ & 4.53 & $\mathbf{8 . 1 8 E}-6$ & $6.25 \mathrm{E}-5$ & $6.7 \mathrm{E}-6$ & $6.97 \mathrm{E}-5$ & $1.39 \mathrm{E}-5$ \\
\hline $7.55 \mathrm{E}-5$ & 5.46 & $7.20 \mathrm{E}-6$ & $8.17 \mathrm{E}-5$ & $6.2 \mathrm{E}-6$ & $8.94 \mathrm{E}-5$ & $1.39 \mathrm{E}-5$ \\
\hline $8.62 \mathrm{E}-5$ & 5.96 & $\mathbf{8 . 2 5 E}-6$ & $9.21 \mathrm{E}-5$ & $5.9 \mathrm{E}-6$ & $1.00 \mathrm{E}-4$ & $1.38 \mathrm{E}-5$ \\
\hline
\end{tabular}

tall concentrations are given in moles/cc

Note that as $\mathrm{HBr}$ is added to the mixture, the pressure increases. The classical equations overpredict the suppression of $\mathrm{HBr}$ while the thermodynamic method predicts an increase, but is not sensitive to the quantity of $\mathrm{HBr}$ added. The dilution of the reactants with $\mathrm{HBr}$ is compensated for by the increase in pressure, keeping the concentrations of $\mathrm{H}_{2}$ and $\mathrm{Br}_{2}$ fixed. The predicted final concentration of $\mathrm{HBr}$ is within 10 percent of the data for both methods. 
The final comparison examines the effect of varying the initial $\mathrm{H}_{2}$ and $\mathrm{Br}_{2}$ concentrations, using the data from Table XI of ref. 6 . The results are shown in Table 5.

Table 5: Effect of Changing Initial Concentrations of $\mathrm{H}_{2}$ and $\mathrm{Br}_{2}$, Temperature $574.3 \mathrm{~K}$

\begin{tabular}{|c|c|c|c|c|c|c|}
\hline $\begin{array}{c}\text { Initial } \\
\mathrm{H}_{2} \\
\text { Mole } \\
\text { Fraction }\end{array}$ & $\begin{array}{c}\text { Initial } \\
\mathrm{Br}_{2} \\
\text { Mole } \\
\text { Fraction }\end{array}$ & $\begin{array}{c}\text { Pressure } \\
\text { atm }\end{array}$ & $\begin{array}{c}\text { Time } \\
\text { minutes }\end{array}$ & $\begin{array}{c}\text { Exper } \\
\mathrm{HBr} \\
\text { moles/cc }\end{array}$ & $\begin{array}{c}\text { Classic } \\
\mathrm{HBr} \\
\text { moles/cc }\end{array}$ & $\begin{array}{c}\text { Thermo } \\
\mathrm{HBr} \\
\text { moles/cc }\end{array}$ \\
\hline 0.657 & 0.343 & 1.805 & 14.5 & $5.97 \mathrm{E}-6$ & $5.38 \mathrm{E}-6$ & $5.65 \mathrm{E}-6$ \\
\hline 0.655 & 0.345 & 0.9252 & 19.5 & $2.87 \mathrm{E}-6$ & $2.67 \mathrm{E}-6$ & $3.78 \mathrm{E}-6$ \\
\hline 0.380 & 0.620 & 1.718 & 15.0 & $4.39 \mathrm{E}-6$ & $4.13 \mathrm{E}-6$ & $1.01 \mathrm{E}-5 \star$ \\
\hline 0.378 & 0.622 & 0.8638 & 15.0 & $1.70 \mathrm{E}-6$ & $1.52 \mathrm{E}-6$ & $5.12 \mathrm{E}-6 \star$ \\
\hline 0.5 & 0.5 & 1.010 & 20.0 & $3.14 \mathrm{E}-6$ & $2.9 \mathrm{E}-6$ & $6.11 \mathrm{E}-6 \star$ \\
\hline 0.5 & 0.5 & 3.787 & 25.0 & $2.44 \mathrm{E}-5$ & $2.24 \mathrm{E}-5$ & $2.75 \mathrm{E}-5$ \\
\hline 0.5 & 0.5 & 2.840 & 15.0 & $1.10 \mathrm{E}-5$ & $9.95 \mathrm{E}-6$ & $1.34 \mathrm{E}-5$ \\
\hline 0.5 & 0.5 & 1.893 & 15.0 & $5.98 \mathrm{E}-6$ & $5.56 \mathrm{E}-6$ & $8.94 \mathrm{E}-6$ \\
\hline
\end{tabular}

$\star$ Indicates large deviation from experimental data

Both the classical and thermodynamic predictions agree well with the experimental data, except for the three starred cases where the $\mathrm{H}_{2}$ was low. For the thermodynamic kinetic set $\mathrm{T} 3\left(0.5 \mathrm{H}_{2}+\mathrm{Br}=\mathrm{HBr}\right)$ is in equilibrium and is waiting for $\mathrm{T} 1\left(\mathrm{Br}_{2}=2 \mathrm{Br}\right)$ for bromine. The time constant for $\mathrm{T} 1$ at the low temperature of $574.3 \mathrm{~K}$ is 60 minutes $\left(1 . / \mathrm{k}_{\mathrm{f}}\right)$. So $\mathrm{HBr}$ can be expressed as:

$$
\mathrm{HBr}=\mathrm{K}_{\mathrm{T} 3} \mathrm{H}_{2}^{1 / 2} \mathrm{Br} ; \frac{\mathrm{dBr}}{\mathrm{dt}}=-2 \frac{\mathrm{dBr}_{2}}{\mathrm{dt}}-\frac{\mathrm{dHBr}}{\mathrm{dt}}
$$

The major difference in deriving mechanisms is that the classical method assumes that $\mathrm{C} 1\left(2 \mathrm{Br}=\mathrm{Br}_{2}\right)$ is equilibrated, whereas in actuality it is the rate controlling step and the rate of formation of $\mathrm{HBr}(\mathrm{T} 3)$ is equilibrated.

This comparison shows that the thermodynamic method is promising for predicting reacting performance. However more examples are required to show that the results are not a peculiarity of the $\mathrm{HBr}$ system. 


\section{Demonstration of Thermodynamic Kinetics Method on the Hydrogen/Oxygen System.}

To determine how the thermodynamic method worked on another system, the first six rates of the H/O system from a recent publication, reference 7 are compared. The ratio of thermodynamic to classical rates are shown in figure 4.

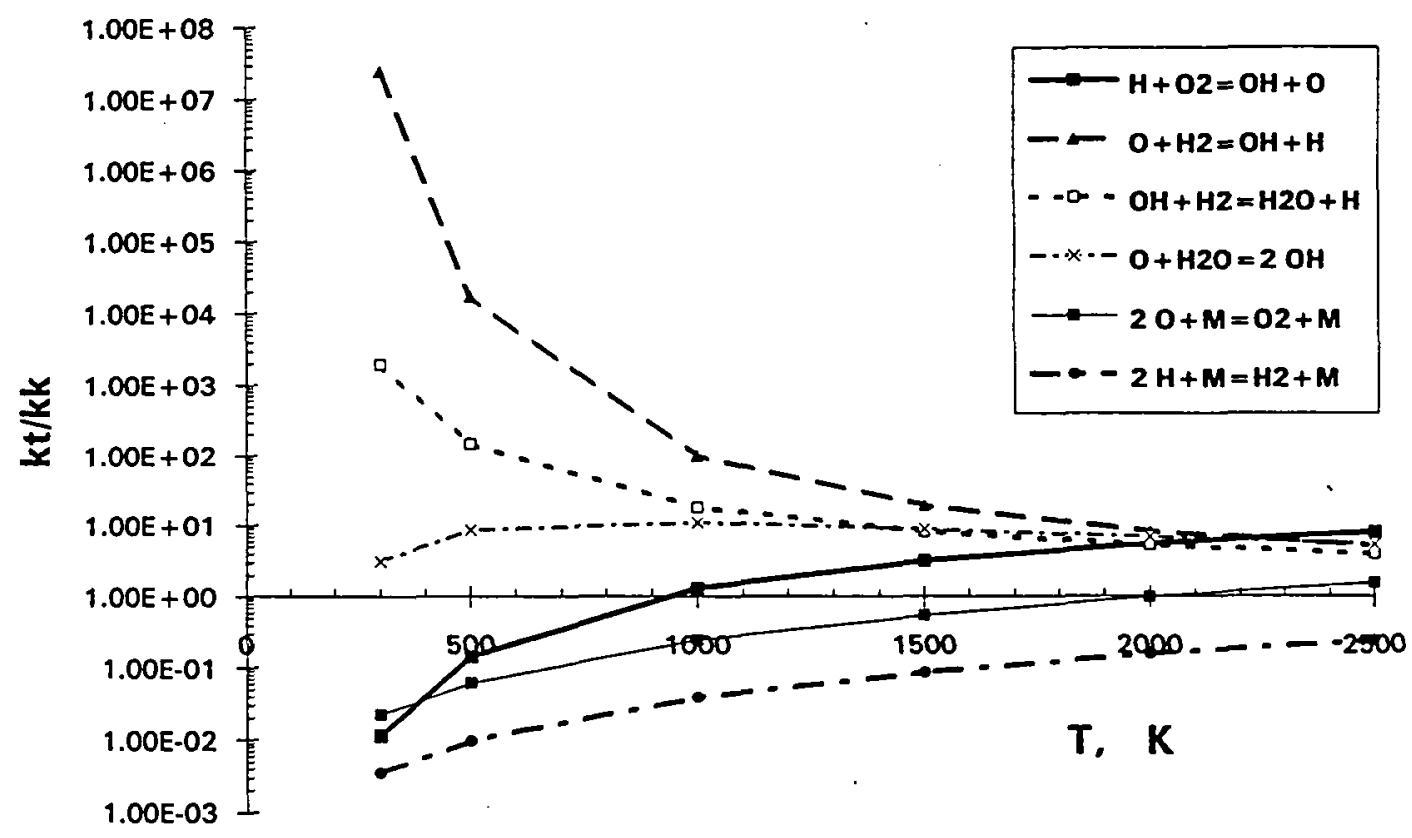

Figure 4. Ratio of thermodynamic kinetics constant to classical kinetics data for some reaction of the Hydrogen/Oxygen system.

At higher temperatures, disagreements were on the order of one order of magnitude; however, at the low temperature of $500 \mathrm{~K}$, the discrepancy is large $10^{4}$ for the $\mathrm{O}+\mathrm{H}_{2}$ reaction. This is because the free radical concentration is low at low temperatures, making measurement accuracy low. Also at low temperature the rates are low so that systematic errors are magnified on a ratio scale. The recommended temperature range for this data is 1400 to $1900 \mathrm{~K}$. The accuracy of the data is estimated to be 13 percent, whereas the deviation of the thermodynamic prediction is an order of magnitude, at high temperature.

The error decreases as the temperature increases, approaching a factor of 10 at $2500 \mathrm{~K}$. Again below $1000 \mathrm{~K}$, the classical kinetic data is an extrapolation of high temperature which may account for the large deviation and errors look bigger. These thermodynamic predictions were made with no change in $D\left(3 \times 10^{8}\right)$. 


\section{Demonstration of the Thermodynamic Kinetic Method} on a Random Selection of Rates

As a final comparison, the thermodynamic kinetic method is compared to the classical method for a random selection of kinetic rates. Rates from reference 4 , five with a thermodynamic constant greater than one, $K_{p}>1$, and then five reactions where $K_{p}<1$ were selected. The first rates listed were with $K_{p}>1$, which turned out to involve the hydrogen atom $\mathrm{H}$. These are shown in figure 5 .

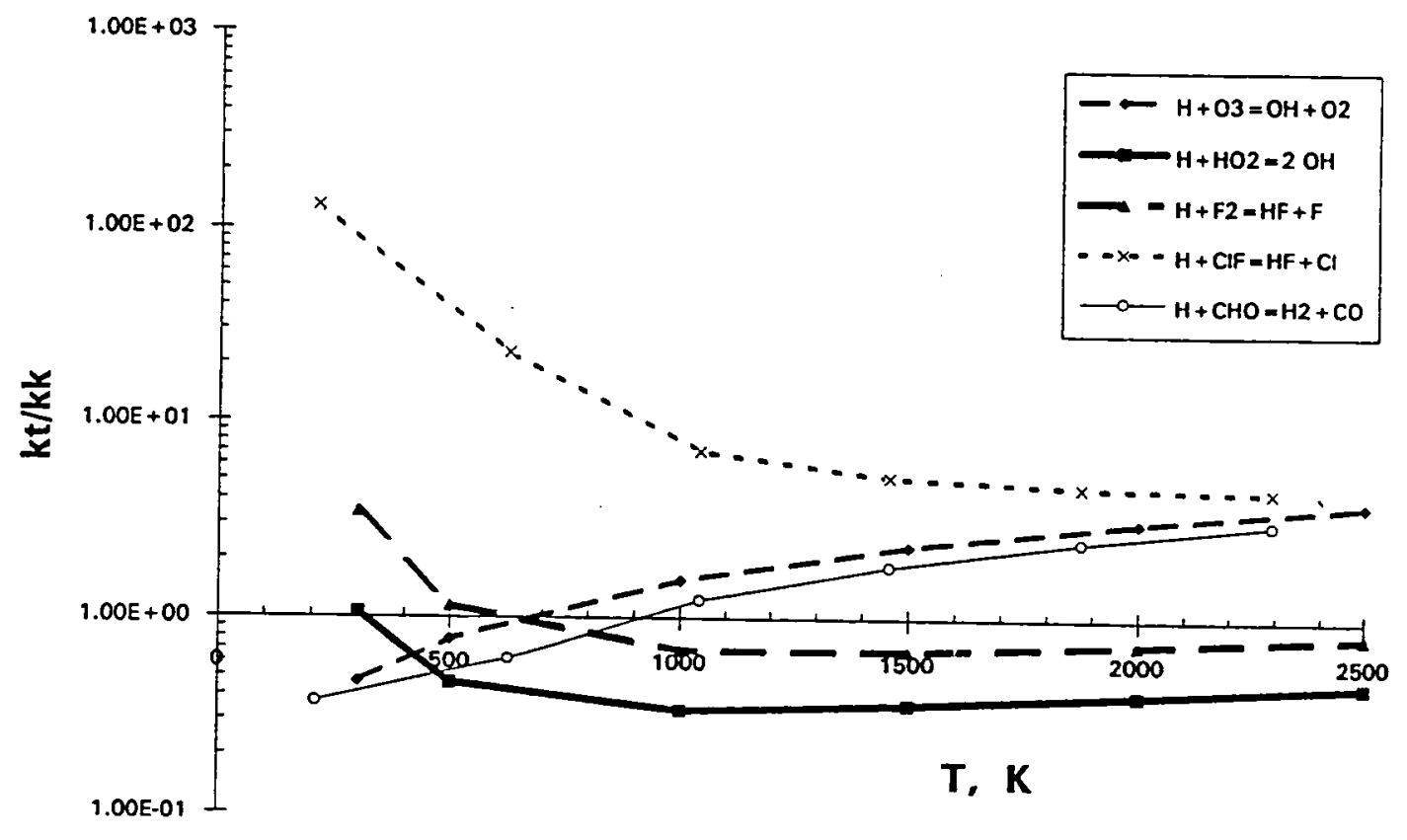

Figure 5. Ratio of thermodynamic rate to kinetic rate for $K_{p}>1$, ref. 4.

When $K_{p}>1$, the rates are given by equation (13) or for a bimolecular reaction the rate is $k_{c f}=D R T$. When $K_{p}>1$, the rate constant is independent of the initial chemical potential, as long as the final chemical potential is below the initial value. The agreement is very good, especially for the ozone $\mathrm{O}_{3}$ and the peroxide $\mathrm{HO}_{2}$ reactions. 
The comparison with $K_{p}<1$ is shown in figure 6 .

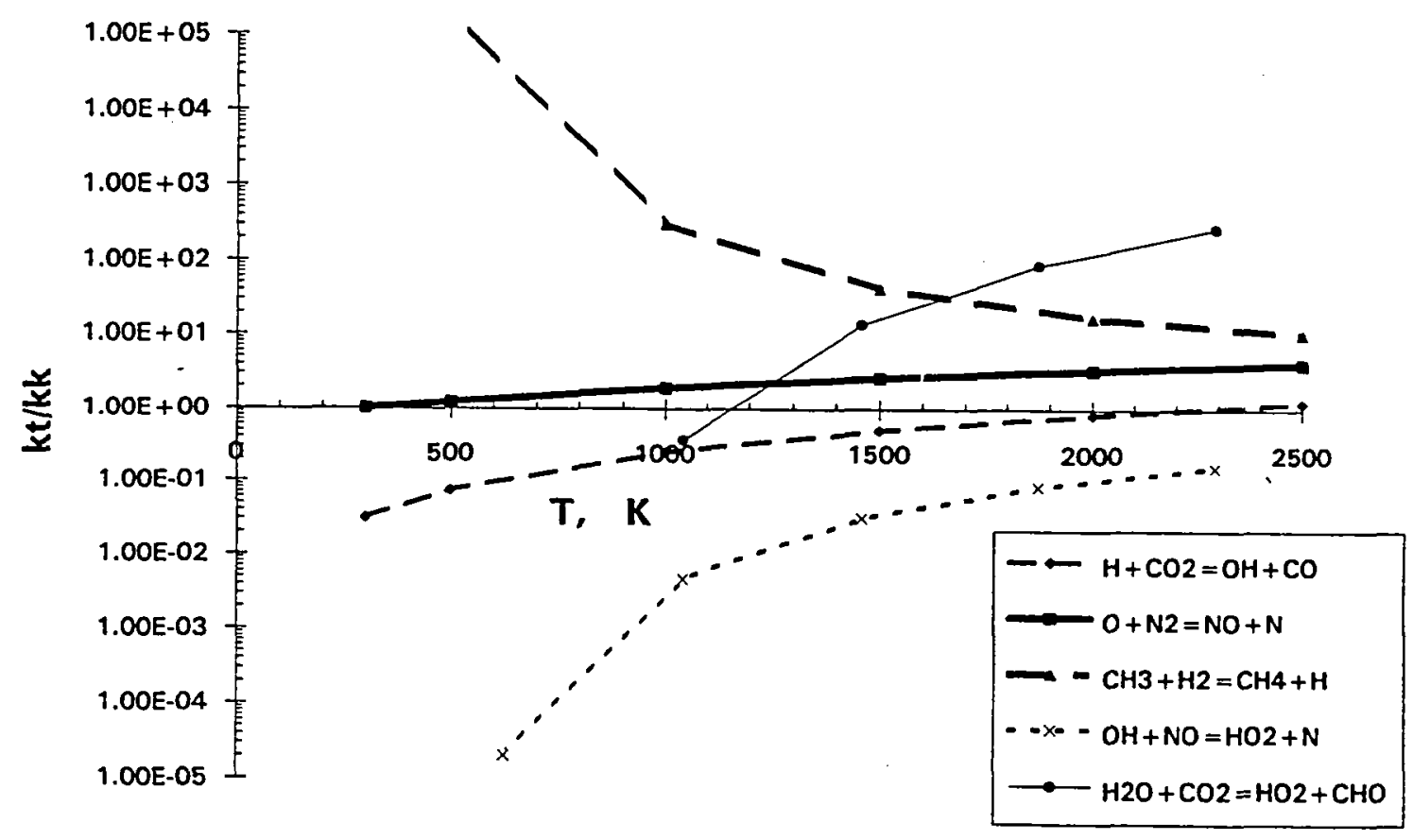

Figure 6: Ratio of thermodynamic rate to kinetic rate for $K_{p}<1$.

Comparing the deviations in figures 5 and figure 6 shows that about the same trends occur with large errors at low temperatures and decreasing as the temperature increased. The value of $D$ is still $3 \times 10^{8}$.

In general the thermodynamic predictions show the same trend as the classical kinetic rates. More comparisons need to be carried out to extensively validate the thermodynamic method for kinetic rate prediction.

\section{Conclusions}

Using thermodynamic data to compute chemical kinetics constants may be a viable alternative for gas phase reactions. The value of the proportionality constant $D$ appears to be universal and equal to $3 \times 10^{8}$ for the cases studied. Changing the value of $D$ would only shift the predicted kinetic rate constant higher or lower for both the forward and reverse rate for the whole temperature range.

The thermodynamic method is given by: 


$$
\begin{gathered}
\mathrm{k}_{\mathrm{c}}=\mathrm{DK} \mathrm{p}_{\mathrm{p}}(\mathrm{RT})^{\Sigma v_{\mathrm{fi}}-1} \text { for } \mathrm{K}_{\mathrm{p}}<1 \text { or } \\
\mathrm{k}_{\mathrm{c}}=\mathrm{D}(\mathrm{RT})^{\Sigma v_{\mathrm{fi}}-1} \text { for } \mathrm{K}_{\mathrm{p}}>1 \\
\text { where } \mathrm{D}=3 \times 10^{8} \mathrm{sec}^{-1} .
\end{gathered}
$$

No specific mechanism is used. All of the species have to interact according to their standard free energy level, $\mu_{i}^{\circ}$. All species have a chance to interact like in the equilibrium code.

There is a strong corellation between the two methods. It is remarkable that for the reactions studied, this simple thermodynamics kinetics model works so well and is consistant for a variety of systems.

\section{References}

1. Gordon, Sanford, and McBride, Bonnie, "Computer Program for Calculation of Complex Chemical Equilibrium Compositions, Rocket Performance, Incident and Reflected Shocks, and Chapman-Jouguet Detonations," NASA SP-273, March 1976.

2. Frenklach, Michael; Wang, Hai; and Rabinowitz, Martin J.; “Optimization and Analysis of Large Chemical Kinetic Mechanisms Using the Solution Mapping Method-Combustion of Methane," Progress in Energy Combustion Science, pp.47-73, Vol. 18, 1992.

3. Britton, Doyle and Cole, Roger M., "Shock Waves in Chemical Kinetics: the Hydrogen-Bromine Reaction," J. Phys. Chem., pp.1302-1308, Vol 65, Aug. 1961.

4. Kondratiev, V.N., "Rate Constants of Gas Phase Reactions," NSRDS-National Standard Refernce Data System, U.S. National Bureau of Standards, COM72-10014, Jan., 1972.

5. Bittker, David A.; "GLSENS, A Generalized Extension of LSENS Including Global Reactions and Added Sensitivity Analysis for the Perfectly Stirred Reactor," NASA TM- , in print.

6. Pease, R.N., "Equilibrium and Kinetics of Gas Reactions," Princeton University Press, Princeton, N.J., pp 112-121, 1942.

7. Ryu, Si-Ok; Hwang, Soon Muk; and DeWitt, Kenneth J.;" High Termperature Kinetic Study of the Reactions $\mathrm{H}+\mathrm{O}_{2}=\mathrm{OH}+\mathrm{O}$ and $\mathrm{O}+\mathrm{H}_{2}=\mathrm{OH}+\mathrm{H}$ in $\mathrm{H}_{2} / \mathrm{O}_{2}$ System by Shock Tube - Laser Absorption Spectroscopy," NASA CR 195473, May 1995. 
Public reporting burden for this collection of information is estimated to average 1 hour per response, including the time for reviewing instructions, searching existing data sources, gathering and maintaining the data needed, and completing and reviewing the collection of information. Send comments regarding this burden estimate or any other aspect of this collection of information, including suggestions for reducing this burden, to Washington Headquarters Services, Directorate for Intormation Coerations and Reports. 1215 Jellerson Davis Highway. Suite 1204, Arlington, VA 22202-4302, and 10 the Otfice of Management and Budget, Papenwork Reduction Projed (0704-0188). Washington, DC 20503.

\begin{tabular}{|l|l|l} 
1. AGENCY USE ONLY (Leave blank) & $\begin{array}{c}\text { 2. REPORT DATE } \\
\text { December 1995 }\end{array}$ & $\begin{array}{r}\text { 3. REPORT TYPE AND DATES COVERED } \\
\text { Technical Memorandum }\end{array}$
\end{tabular}

\section{TITLE AND SUBTITLE}

5. FUNDING NUMBERS

Calculation of Kinetic Rate Constants From Thermodynamic Data

6. AUTHOR(S)

C. John Marek

WU-505-62-52

B. PERFORMING ORGANIZATION

7. PERFORMING ORGANIZATION NAME(S) AND ADDRESS(ES)

National Aeronautics and Space Administration

Lewis Research Center

Cleveland, Ohio 44135-3191

\section{REPORT NUMBER}

E-10043
9. SPONSORINGMONITORING AGENCY NAME(S) AND ADDRESS(ES)

National Aeronautics and Space Administration

Washington, D.C. 20546-0001
10. SPONSORING/MONITORING AGENCY REPORT NUMBER

NASA TM-107124

AIAA-96-0218

\section{SUPPLEMENTARY NOTES}

Prepared for the 34th Aerospace Sciences Meeting \& Exhibit sponsored by the American Institute of Aeronautics and Astronautics, Reno, Nevada, January 15-18, 1996. Responsible person, C. John Marek, organization code 2560, (216) 433-3584.

12a. DISTRIBUTIONAVAILABILITY STATEMENT

12b. DISTRIBUTION CODE

Unclassified - Unlimited

Subject Category 07

This publication is available from the NASA Center for Aerospace Information, (301) 621-0390.

13. ABSTRACT (Maximum 200 words)

A new scheme for relating the absolute value for the kinetic rate constant $k$ to the thermodynamic constant $K_{p}$ is developed for gases. In this report the forward and reverse rate constants are individually related to the thermodynamic data. The kinetic rate constants computed from thermodynamics compare well with the current kinetic rate constants. This method is self consistent and does not have extensive rules. It is first demonstrated and calibrated by computing the $\mathrm{HBr}$ reaction from $\mathrm{H}_{2}$ and $\mathrm{Br}_{2}$. The method then is used on other reactions.

14. SUBJECT TERMS

Combustion; Kinetics; Hydrogen bromine; Thermodynamic data 15. NUMBER OF PAGES 18

Combustion, Kinetics, Hydrogen bromine, Thermodynamic data

\begin{tabular}{l|c}
\hline $\begin{array}{c}\text { 17. SECURTYY CLASSIFICATION } \\
\text { OF REPORT } \\
\text { Unclassified }\end{array}$ & $\begin{array}{c}\text { 18. SECURTY CLASSIFICATION } \\
\text { OF THIS PAGE } \\
\text { Unclassified }\end{array}$ \\
\hline
\end{tabular}
19. SECURITY CLASSIFICATION OF ABSTRACT Unclassified 
National Aeronautics and

Space Administration

Lewis Research Center

21000 Brookpark Rd.

Cleveland, $\mathrm{OH}$ 44135-3191

Official Business

Penalty for Private Use $\$ 300$

POSTMASTER: If Undeliverable - Do Not Return 